\title{
Increased detection of Plasmodium knowlesi in Sandakan division, Sabah as revealed by PlasmoNex ${ }^{\text {TM }}$
}

Xiang Ting Goh ${ }^{1}$, Yvonne AL Lim ${ }^{*}$, Indra Vythilingam ${ }^{1}$, Ching Hoong Chew ${ }^{2}$, Ping Chin Lee ${ }^{3}$, Romano Ngui ${ }^{1}$, Tian Chye Tan ${ }^{1}$, Nan Jiun Yap ${ }^{1}$, Veeranoot Nissapatorn ${ }^{1}$ and Kek Heng Chua ${ }^{2^{*}}$

\begin{abstract}
Background: Plasmodium knowlesi is a simian malaria parasite that is widespread in humans in Malaysian Borneo. However, little is known about the incidence and distribution of this parasite in the Sandakan division, Malaysian Borneo. Therefore, the aim of the present epidemiological study was to investigate the incidence and distribution of $P$. knowlesi as well as other Plasmodium species in this division based on a most recent developed hexaplex PCR system (PlasmoNex ${ }^{\mathrm{TM}}$.

Methods: A total of 189 whole blood samples were collected from Telupid Health Clinic, Sabah, Malaysia, from 2008 to 2011. All patients who participated in the study were microscopically malaria positive before recruitment. Complete demographic details and haematological profiles were obtained from 85 patients ( 13 females and 72 males). Identification of Plasmodium species was conducted using PlasmoNex ${ }^{\mathrm{TM}}$ targeting the 18S ssu rRNA gene.

Results: A total of 178 samples were positive for Plasmodium species by using PlasmoNex ${ }^{\mathrm{TM}}$. Plasmodium falciparum was identified in 68 samples (38.2\%) followed by 64 cases (36.0\%) of Plasmodium vivax, 42 (23.6\%) cases of P. knowlesi, two (1.1\%) cases of Plasmodium malariae and two (1.1\%) mixed-species infections (i e, P. vivax) P. falciparum). Thirty-five PlasmoNex ${ }^{\mathrm{TM}}$ positive $P$. knowlesi samples were misdiagnosed as $P$. malariae by microscopy. Plasmodium knowlesi was detected in all four districts of Sandakan division with the highest incidence in the Kinabatangan district. Thrombocytopaenia and anaemia showed to be the most frequent malaria-associated haematological complications in this study.

Conclusions: The discovery of P. knowlesi in Sandakan division showed that prospective studies on the epidemiological risk factors and transmission dynamics of $P$. knowlesi in these areas are crucial in order to develop strategies for effective malaria control. The availability of advanced diagnostic tool PlasmoNex ${ }^{\mathrm{TM}}$ enhanced the accuracy and accelerated the speed in the diagnosis of malaria.
\end{abstract}

\section{Background}

Malaria, a tropical disease caused by infection with single-celled parasites of the genus Plasmodium, is one of the most deadly parasitic diseases in the world. According to the World Malaria Report 2011, an estimated 3.3 billion people were at risk of malaria in 2010. Of this total, 2.1 billion people were at low risk whereas

\footnotetext{
*Correspondence: limailian@um.edu.my; khchua@um.edu.my

'Department of Parasitology, Faculty of Medicine, University of Malaya, Kuala Lumpur, Malaysia

${ }^{2}$ Department of Molecular Medicine, Faculty of Medicine, University of Malaya, Kuala Lumpur, Malaysia

Full list of author information is available at the end of the article
}

1.2 billion people were at high risk (>one case per 1,000 population) and living mostly in the WHO African (47\%) and Southeast Asian regions (37\%) [1]. Malaria is the most common vector-borne parasitic disease in Malaysia, responsible for 20-40 deaths per year over the last decade, and it is estimated that 3\% of total Malaysian population live in malaria risk areas. Around $80 \%$ of nationwide cases are found in Malaysian Borneo with 58\% occurring in the northern state of Sabah and less than 20\% of total malaria cases occurring in Peninsular Malaysia [2].

In Sabah, malaria is transmitted by various Anopheles mosquitoes, such as Anopheles balabacensis, Anopheles sundaicus and Anopheles flavirostris [3]. Traditionally,

\section{Ciomed Central}


human malaria can be caused by four Plasmodium species, which include Plasmodium falciparum, Plasmodium vivax, Plasmodium malariae and Plasmodium ovale. These four Plasmodium species are well-recognized to cause human malaria worldwide [4]. Infection caused by P. falciparum is severe and may be fatal in the absence of prompt recognition of the disease and its complications, while the disease caused by $P$. vivax, $P$. ovale and $P$. malariae is usually milder and rarely fatal.

Recently, a simian malaria parasite, Plasmodium knowlesi, has been recognized as the fifth human malaria species by WHO [5]. Plasmodium knowlesi is a malaria parasite of Old World monkeys, which was formerly known to cause malaria only in macaques [6]. However, this parasitic infection is widespread in humans in Malaysia and has been reported from Malaysian Borneo [7-11] and Peninsular Malaysia [8,12-14]. This infection has also been reported in Singapore [15-17], Thailand $[18,19]$, Myanmar [20,21], Philippines [22], Indonesia [23,24], Vietnam [25] and Cambodia [26], pinpointing that the incidence of $P$. knowlesi was generally high in Southeast Asian countries especially Malaysia. Unfortunately, this parasite is life-threatening and has caused mortality in humans $[27,28]$.

The diagnosis of $P$. knowlesi infection can be challenging for an inexperienced microscopist because the early trophozoite stages of this parasite are morphologically similar to those of P. falciparum [7,29] whilst the later erythrocytic stages (i.e., late trophozoites, schizonts and gametocytes) of $P$. knowlesi are indistinguishable from $P$. malariae [7], including the presence of the typical band-forms. Due to these morphological similarities between $P$. knowlesi and P. malariae, naturally acquired $P$. knowlesi infections are often misdiagnosed via microscopy as $P$. malariae $[7,29]$.

This was evident when six out of 14 malaria deaths reported in Sabah during 2010-2011 [28] were actually caused by $P$. knowlesi (later diagnosis done with molecular tools) but were diagnosed initially as $P$. malariae infections via microscopy detection. Hence, in order to overcome the limitations of microscopy for the detection of malaria, molecular tools such as polymerase chain reaction (PCR) are necessary for accurate identification of $P$. knowlesi as well as other Plasmodium parasites in order to avoid mortality. This method has proven to be more specific and sensitive than conventional microscopy [30]. Recognizing this advantage, the utilization of molecular techniques in diagnosis and research in molecular epidemiology has become more common. Recently, in a study based on nested PCR assay, a total of 107 malaria cases (44\% of 243 samples) have been reported in four districts in the interior division of western Sabah (i.e., Keningau, Tenom, Tambunan, Nabawan) [31].

However, information on malaria incidence in eastern districts of Sabah is scarce. Therefore, the aim of the present epidemiological study was to investigate the incidence and distribution of the Plasmodium species in these districts of Sabah, Malaysian Borneo based on a most recent developed hexaplex PCR system in order to obtain accurate epidemiological data which serves as an important foundation in the effectiveness of malaria control strategy. The straightforward single-step hexaplex PCR system (commercial name PlasmoNex ${ }^{\mathrm{mix}}$ ) targeting five human Plasmodium $18 \mathrm{~s}$ small subunit rRNA (ssu rRNA) was developed by Chew et al. [32]. This system can detect all five human Plasmodium species simultaneously as well as mixed infections in a single step PCR with high sensitivity and specificity. Therefore, this system was the method of choice for the detection of malaria parasites in this study instead of nested PCR because it is rapid and less labour-intensive.

\section{Methods}

\section{Study area and population}

Sabah is one of the 13 member states of Malaysia. It is situated at the northern part of Borneo Island and it shares a land border with Sarawak and Indonesia. This state covers an area of 73,620.1 sq km, comprising of 24 districts with a population of 3,120,040 people. Sabah is a famous tourist destination (e.g., Mount Kinabalu and Sipadan Island). Currently, there are more than 30 officially recognized ethnic groups in Sabah, the largest indigenous groups being the Kadazan-Dusun people, followed by Bajau and Murut. Chinese is the largest non-indigenous ethnic in Sabah. In this research, samples of the studied subjects were obtained from four districts (i.e., Kinabatangan, Beluran, Sandakan, Tongod) within Sandakan division which is the largest division in Sabah. It has approximately $19.4 \%$ of Sabah's total population and covers an area of 28,205 sq km. A majority of the ethnic groups in Sandakan division are Chinese, Suluk and Bajau Simunul. Tongod is at the central part of Sabah, whereas Kinabatangan, Beluran and Sandakan are situated in the eastern part of Sabah.

The major economic contributions for Sandakan division are oil palm plantation, timber and eco-tourism. Most of the indigenous populations in this region reside in communities close to palm oil plantations or dense rain forest. This region is surrounded by forest fringe, contains an array of wildlife habitat, which usually act as a natural habitat for the hosts of $P$. knowlesi, the longtailed (Macaca fascicularis) and pig-tailed (Macaca nemestrina) macaques as well as the vectors (i.e., Anopheles leucosphyrus group of mosquitoes).

\section{Clinical sample collection}

A total of 189 whole blood samples were collected from Telupid Health Clinic, Sabah, Malaysia, from 2008 to 2011. Telupid Health Clinic is the only diagnostic 
laboratory in Sandakan Division outside of Sandakan town. Usually, patients in Sandakan town receive treatment at the Sandakan Hospital. However, this hospital is about $130 \mathrm{~km}$ away from Telupid Health Clinic and it takes about 2-3 hours drive to get there. Therefore, samples from Sandakan and neighbouring districts may be sent to Telupid Health Clinic for diagnosis. Blood samples were collected from Blood Film for Malaria Parasites (BFMP)-positive patients who attended the clinic. The patients who participated in the study were all microscopically malaria positive patients before recruitment. Blood samples included in the study were collected from Sandakan and neighbouring districts such as Kinabatangan, Beluran and Tongod. In this study, $3 \mathrm{ml}$ of blood was collected from each BFMP-positive patient that attended the clinic by qualified medical laboratory staff. A small amount of each sample was used for routine haematological profiling in the laboratory, and genomic DNA was extracted from the remaining sample. Basic demographic data of the patients if available, was obtained and recorded. Complete demographic details and haematological profiles were obtained from 85 patients (13 females and 72 males).

\section{Ethics statement}

Patients' consent was obtained prior to blood sample collection. For all child participants, parents/guardians provided the consent on their behalf. This study was approved by the Ethics Committee reviewer board of University of Malaya Medical Center (UMMC), Malaysia (MEC reference number 709.2).

\section{Laboratory procedures}

\section{Conventional microscopic examination}

Blood smears were prepared prior to anti-malarial treatment for patients with suspected malaria. The thick and thin blood smears were stained with Giemsa and examined by experienced microscopist at the Telupid Health Clinic, Sabah. All blood smears were examined under the microscope at a magnification of $\times 1000$ with immersion oil. Routine diagnosis reports were prepared by medical laboratory staff at this clinic. Species of parasites were determined based on the morphology of parasites. Parasite developmental stages such as early trophozoite, late and mature trophozoite, schizonts, and gametocytes were determined and recorded.

\section{Determination of parasitaemia}

The parasitaemia of infected patients in this study was estimated using a simple modified method, which involved counting of parasites in thin blood films by using the plus system [33]. A code of between one to four plus signs was used to estimate the parasitaemia of parasites whereby $+=1-10$ parasites per 100 thin film fields or
4-40 parasites $/ \mu \mathrm{L},++=11-100$ parasites per 100 thin film fields or $\sim 41-400$ parasites $/ \mu \mathrm{L},+++=1-10$ parasites per single thin film fields or $\sim 401-4,000$ parasites/ $\mu \mathrm{L}$, and $++++=$ more than ten parasites per single thin film fields or $>4,000$ parasites $/ \mu \mathrm{L}$ of blood [11]. Blood films were interpreted as negative if no parasite was observed in 200 microscopic fields.

\section{Haematological profiles}

Haematological profiles of patients such as haemoglobin level $(\mathrm{Hb})$, platelet counts and total white blood cell counts (TWBC) were obtained and analysed. All these laboratory procedures were carried out at the Telupid Health Clinic, Sabah. Anaemia was confirmed when the $\mathrm{Hb}$ level is $<110 \mathrm{~g} / \mathrm{L}$ for children aged six months to two years, $<115 \mathrm{~g} / \mathrm{L}$ for children five to 11 years, $<120 \mathrm{~g} / \mathrm{L}$ for children 12-14 years, $<120 \mathrm{~g} / \mathrm{L}$ for women and $<130 \mathrm{~g} / \mathrm{L}$ for men [34]. Thrombocytopaenia was determined when platelet counts were $<150,000$ cells $/ \mathrm{cmm}$. Patients were divided into three subgroups based on the platelet count. Thrombocytopaenia was considered severe if $<50,000$ cells $/ \mathrm{cmm}$, moderate if 50,000-100,000 cells/cmm and mild if 100,000-150,000 cells $/ \mathrm{cmm}$. TWBC count for a normal adult is $4.3-10.8$ cells/L and children have a slightly higher TWBC count which is 4.5-11.0 cells/L. Leukopaenia was determined when the TWBC count for an adult was 3.0-5.0 cells/L, and for leukocytosis was $11.0-17.0$ cells/L.

\section{Extraction of genomic DNA}

DNA template for the hexaplex PCR assay was extracted from $200 \mu$ l thawed EDTA-blood using the QiAamp DNA Blood Mini Kit (Hilden, Germany), following the manufacturer's recommendations. Approximately $100 \mu \mathrm{l}$ of DNA template were obtained from the blood and $1.5 \mu$ of DNA template was used for the hexaplex PCR assay. The extracted DNA was kept in $-20^{\circ} \mathrm{C}$ until further use.

\section{Detection of Plasmodium species using PlasmoNex ${ }^{\mathrm{TM}}$}

Identification of Plasmodium species was conducted using PlasmoNex ${ }^{\mathrm{Tm}}$ targeting the $18 \mathrm{~S}$ ssu rRNA gene [32]. PCR amplification was performed in $15 \mu \mathrm{L}$ reaction mixture containing $1 \mathrm{X}$ PCR buffer, $3.0 \mathrm{mM} \mathrm{MgCl}_{2}$, $0.2 \mathrm{mM}$ of dNTP mix, Plasmodium primer mixture, $1 \mathrm{U}$ of Taq DNA polymerase and $1.5 \mu \mathrm{L}(\sim 10 \mathrm{ng})$ of template DNA. Cycling condition of the PCR amplification was as follows: initial denaturation at $95^{\circ} \mathrm{C}$ for $5 \mathrm{~min}, 35$ amplification cycles at $95^{\circ} \mathrm{C}$ for $30 \mathrm{sec}, 56^{\circ} \mathrm{C}$ for $30 \mathrm{sec}$, and $65^{\circ} \mathrm{C}$ for $40 \mathrm{sec}$, followed by final extension at $65^{\circ} \mathrm{C}$ for $10 \mathrm{~min}$ in a thermal cycler (BIO-RAD, Germany). The amplified products were visualized on a $3.0 \%(\mathrm{w} / \mathrm{v})$ agarose gel stained with ethidium bromide. 


\section{Statistical analysis}

Statistical analysis was carried out using the SPSS software programme for Windows version 17 (SPSS, Chicago, IL, USA). The intensity of malaria infections (parasitaemia) was estimated by a simple modified method which involved counting of parasite numbers in thin blood films by using the plus system and was categorized into four main categories:,,++++++ and ++++ . For descriptive data, percentage was used to describe the characteristics of the studied population, including the prevalence of anaemia, thrombocytopaenia, leukopaenia and leukocytosis. The distribution of $\mathrm{Hb}$, platelet and TWBC were presented as median and interquartile range (IQR) after being examined for normality using the Shapiro-Wilk test. The correlation between continuous variables was examined using Spearman's correlation coefficients $\left(r_{s}\right)$ test as they were not normally distributed. A Pearson's Chi-square $\left(\mathrm{X}^{2}\right)$ test was used to test the association between each variable. The level of statistical significance was set at $\mathrm{p}<0.05$ for each test. For each of the statistically significant variable, odd ratios (ORs) and 95\% confidence interval $(95 \% \mathrm{CI})$ were calculated to explore the association between variables of interest.

\section{Results}

\section{Incidence and distribution of Plasmodium species based} on microscopy

A total of 189 BFMP-positive samples were collected during the study period at Telupid Health Clinic, Sabah. Based on microscopy, 38.6\% (73/189) were P. falciparum, 33.9\% (64) were $P$. vivax, 25.9\% (49) were $P$. malariae, $1.1 \%$ (two) were mixed $P$. vivax $/ P$. malariae and $0.5 \%$ (one) was mixed $P$. falciparum $/ P$. vivax infections (Table 1). Of the $P$. vivax-positive blood films, 92.2\% (59/64) had asexual parasites only, 7.8\% (five) had both asexual parasites and gametocytes. For $P$. falciparum-positive blood films, 60.3\% (44/73) had asexual parasites alone, 39.7\% (29) had asexual parasites and gametocytes. As for P. malariae-positive blood films, 98.0\% (48/49) had asexual parasites alone while only $2.0 \%(1 / 49)$ had both asexual parasites and gametocytes
(Table 2). There was no P. knowlesi and P. ovale malaria infection reported from the microscopic examination.

Given that the complete demographic details and haematological profiles could only be obtained from 85 patients (i.e., 13 females and 72 males), the results pertaining to demographic and haematological profiles will be based on 85 and not 189 patients. The ethnicities of patients that participated in this study were Dusun (50.6\%), Bugis (18.8\%), Filipinos (5.9\%), Rung (4.7\%) and others . Among the four districts of Sandakan division, Kinabatangan has the highest malaria cases detected (35 cases; $41.2 \%$ of 85 ) in this study followed by Sandakan (22 cases; 25.9\%), Beluran (16 cases; $18.8 \%$ ) and lastly Tongod (12 cases; 14.1\%).

With regard to the age groups, there was a total of 19 children and 66 adults. The age range was between two to 60 years old ( mean $=24.8$ years; median $=24.0$ years ). Malaria was more prevalent among adults (77.6\%) compared to children (22.4\%). With regard to gender, male patients $(84.7 \%)$ were almost five-fold more compared to female patients (15.3\%) (Table 3). Generally, malaria was prevalent among adults especially male.

According to the haematological profiles, the present study showed that the overall median concentration of $\mathrm{Hb}$, platelet count and TWBC for the patients was $128.0 \mathrm{~g} / \mathrm{l}(\mathrm{IQR}=109.0-140.0), 91,000 \mathrm{cells} / \mathrm{cmm}(\mathrm{IQR}=$ $61,500-132,500)$ and TWBC was $6.6 \times 10^{9}$ cells/L (IQR = 5.1-8.8), respectively (Table 3 ). Overall, the $\mathrm{Hb}$ level among malaria patients were at the borderline of normal $\mathrm{Hb}$ level (>120 g/l for woman and >130 g/l for man), however, the platelet level of patients were much lower than the normal platelet count $(>150,000$ cells $/ \mathrm{cmm})$. TWBC of malaria patients in this study were within the normal range $\left(4.5-10.0 \times 10^{9}\right.$ cells/L). The median $\mathrm{Hb}$ value (107 g/l; range: $86-111)$ and TWBC count $(5.9 \times$ $10^{9}$ cells/L; range: $\left.5.3-9.3\right)$ among infected children were lower than the $\mathrm{Hb}$ value (134 $\mathrm{g} / \mathrm{l}$; range: 121-142) and TWBC count $\left(6.75 \times 10^{9}\right.$ cells/L; range: $\left.5.0-8.6\right)$ of adults. However, the platelet count among infected children (102,000 cells/cmm; range: 73,000-180,000) was higher when compared to the adults $(88,500$ cells/cmm;

Table 1 Comparison of diagnosis of Plasmodium species by microscopy and PlasmoNex ${ }^{\mathrm{TM}}$ for the samples collected from eastern and central Sabah $(\mathrm{N}=189)$

\begin{tabular}{|c|c|c|c|c|c|c|c|}
\hline \multirow[b]{2}{*}{ Microscopy results } & \multicolumn{7}{|c|}{ No. of cases identified based on PCR examination } \\
\hline & P. falciparum & P. vivax & P. knowlesi & P. malariae & $\begin{array}{l}P . \text { falciparum } \\
\text { and } P \text {. vivax }\end{array}$ & Negative & $\begin{array}{l}\text { No. of cases identified } \\
\text { by microscopy }\end{array}$ \\
\hline P. falciparum & 62 & 2 & 4 & 0 & 0 & 5 & 73 \\
\hline P. vivax & 0 & 58 & 3 & 0 & 0 & 3 & 64 \\
\hline P. malariae & 6 & 3 & 35 & 2 & 0 & 3 & 49 \\
\hline P.vivax and P. malariae & 0 & 1 & 0 & 0 & 1 & 0 & 2 \\
\hline$P$. falciparum and $P$. vivax & 0 & 0 & 0 & 0 & 1 & 0 & 1 \\
\hline Total & 68 & 64 & 42 & 2 & 2 & 11 & 189 \\
\hline
\end{tabular}


Table 2 Parasite developmental stage in this study $(\mathrm{n}=186)^{\mathrm{a}}$

\begin{tabular}{lcccccc}
\hline \multirow{2}{*}{ Species } & \multicolumn{4}{c}{ Developmental stages } \\
\cline { 2 - 4 } & $\mathbf{N}$ & \multicolumn{2}{c}{ Asexual } & & Asexual + Gametocytes \\
\cline { 3 - 4 } \cline { 6 - 7 } & & $\mathbf{n}$ & $\%$ & & $\mathbf{n}$ & $\%$ \\
\hline P. falciparum & 73 & 44 & 60.3 & & 29 & 39.7 \\
P. vivax & 64 & 59 & 92.2 & & 5 & 7.8 \\
P. malariae & 49 & 48 & 98.0 & & 1 & 2.0 \\
*P. knowlesi & 42 & 40 & 95.2 & & 2 & 4.8 \\
\hline
\end{tabular}

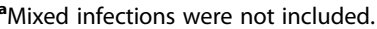

*PlasmoNex ${ }^{\mathrm{TM}}$ confirmed $P$. knowlesi cases.

range: 55,750-127,000). With regard to gender, male had higher $\mathrm{Hb}$ value (132 g/l; range: 119-142) and platelet count $(94,000$ cells/cmm; range: $61,500-132,750)$ compared to female's $\mathrm{Hb}$ value (107 $\mathrm{g} / \mathrm{l}$; range: $75-114)$ and platelet count $(87,000$ cells $/ \mathrm{cmm}$; range: $60,500-$ $131,500)$. However, the TWBC count of female $\left(6.9 \times 10^{9}\right.$ cells/L; range: 4.4-9.6) was slightly higher than male $\left(6.6 \times 10^{9}\right.$ cells/L; range: 5.2-8.3).

Study showed that an overall of $48.2 \%$ (41/85) of the patients had anaemia, 56.5\% (48/85) had thrombocytopaenia, 8.2\% (7/85) had leukopenia and 7.1\% (6/85) had leukocytosis (Table 3). The prevalence of anaemia, thrombocytopaenia, leukopaenia and leukocytosis were further analysed according to age and gender (Table 3). The prevalence of anaemia was found to be significantly associated with age and gender. The prevalence of anaemia was significantly higher in children $\left(x^{2}=6.30\right.$; $\mathrm{p}=0.012)$ compared to adult. Study also showed that children had higher risk $(\mathrm{OR}=1.8 ; 95 \% \mathrm{CI}=1.213$ 2.674) of getting anaemia compared to the adults. With regard to gender, it was observed that anaemia was significantly higher in female $\left(\mathrm{x}^{2}=5.1 ; \mathrm{p}=0.025\right)$ compared to male. The risk of female suffering anaemia was 1.8 times higher than male $(\mathrm{OR}=1.8 ; 95 \% \mathrm{CI}=1.199-2.663)$.

However, the prevalence of thrombocytopaenia, leukopaenia and leukocytosis were not significantly associated with age and gender. Although the prevalence of thrombocytopaenia in adult (59.1\%) was higher compared to children (47.4\%), the difference was not statistically significant. Similarly, there was no significant difference between leukopaenia and leukocytosis with age although the prevalence of leukopaenia was higher in children (10.5\%) and leukocytosis was higher in adult (7.6\%). There was also no significant difference between thrombocytopaenia, leukopaenia and leukocytosis with gender.

\section{Incidence and distribution of Plasmodium species based on PlasmoNex ${ }^{\mathrm{Tm}}$}

Out of the 189 samples analysed, a total of 178 samples were positive for Plasmodium species by using Plasmo$\mathrm{Nex}^{\mathrm{m}}$, however, 11 (5.8\%) samples were found to be negative. Plasmodium falciparum was identified in 68 samples $(38.2 \%)$ which was the highest number of species detected by PlasmoNex ${ }^{\text {tw }}$ in this study followed by 64 cases $(36.0 \%)$ of $P$. vivax and $42(23.6 \%)$ cases of P. knowlesi and two (1.1\%) cases of P. malariae. Overall, only two $(1.1 \%)$ of the samples were found to have mixed-species infections (i.e., $P$. vivax/P. falciparum) by PlasmoNex ${ }^{\mathrm{Tm}}$. For PlasmoNex ${ }^{\mathrm{Tm}}$ confirmed P. knowlesi infection, there were only $4.8 \%$ of the samples $(2 / 42)$ that had both asexual parasites and gametocytes while $95.2 \%$ of the samples (40/42) had only asexual stages.

Of the 49 samples which were reported as $P$. malariae by microscopy examination, only two $(1.1 \%)$ were found to be $P$. malariae by PlasmoNex ${ }^{\text {Ta }}$ (Table 1). Thirty-five (71.4\% of 49) cases of P. knowlesi were microscopically misdiagnosed as $P$. malariae in this study. Besides, four

Table 3 Distribution of hematological status among malaria infected patients in this study $(n=85)^{a}$

\begin{tabular}{|c|c|c|c|c|c|c|c|c|c|c|c|c|}
\hline \multirow[b]{3}{*}{ Age/Gender } & \multirow[b]{3}{*}{$\mathbf{N}$} & \multirow{3}{*}{$\begin{array}{c}\mathrm{Hb}(\mathrm{g} / \mathrm{l}) \\
\text { Median (IQR) }\end{array}$} & \multirow{3}{*}{$\begin{array}{c}\text { Platelet (cells/cmm) } \\
\text { Median (IQR) }\end{array}$} & \multirow{3}{*}{$\begin{array}{c}\text { TWBC } \\
\left(10^{9} \text { cells/L) }\right. \\
\text { Median (IQR) }\end{array}$} & \multirow{2}{*}{\multicolumn{2}{|c|}{ Anaemia $^{\mathbf{b}}$}} & \multirow{2}{*}{\multicolumn{2}{|c|}{$\begin{array}{l}\text { Thrombocyto- } \\
\text { peniac }^{c}\end{array}$}} & \multicolumn{4}{|c|}{ White blood cell count } \\
\hline & & & & & & & & & \multicolumn{2}{|c|}{ Leukopenia $^{d}$} & \multicolumn{2}{|c|}{ Leukocytosis ${ }^{\mathrm{e}}$} \\
\hline & & & & & No. & $\%$ & No. & $\%$ & No. & $\%$ & No. & $\%$ \\
\hline \multicolumn{13}{|l|}{ Age (year) } \\
\hline Children (0-14) & 19 & 107(86-111) & $102000(73000-180000)$ & $5.9(5.3-9.3)$ & 14 & $73.7 *$ & 9 & 47.4 & 2 & 10.5 & 1 & 5.3 \\
\hline Adult (>15 years) & 66 & $134(121-142)$ & 88500 (55750-127000) & $6.75(5.0-8.6)$ & 27 & 40.9 & 39 & 59.1 & 5 & 7.5 & 5 & 7.6 \\
\hline \multicolumn{13}{|l|}{ Gender } \\
\hline Male & 72 & $132(119-142)$ & 94000 (61500-132750) & $6.6(5.2-8.3)$ & 31 & 43.1 & 40 & 55.6 & 5 & 6.9 & 6 & 8.3 \\
\hline Female & 13 & $107(75-114)$ & 87000 (60500-131500) & $6.9(4.4-9.6)$ & 10 & $76.9 *$ & 8 & 61.5 & 2 & 15.4 & 0 & 0 \\
\hline *Total & 85 & $128(109-140)$ & $91000(61500-132500)$ & $6.6(5.1-8.8)$ & 41 & 48.2 & 48 & 56.5 & 7 & 8.2 & 6 & 7.1 \\
\hline
\end{tabular}

*Total samples were based on 85 microscopic positive samples that had both complete demographic and hematological data. $\mathrm{N}$ : number examined; IQR: inter quartile range.

${ }^{a}$ Distribution of anaemia, thrombocytopenia, leukopenia and leukocytosis according to gender and age groups was based on 85 microscopic positive samples.

${ }^{b}$ Haemoglobin $(\mathrm{Hb})$ below age-specific threshold (see methodology).

cPlatelet counts $<150,000$ cells $/ \mathrm{cmm}$.

${ }^{\mathrm{d}}$ Total white blood cells counts was $3.0-5.0$ cells/L.

'Total white blood cells counts was $11.0-17.0$ cells/L.

$*$ Significant difference $(p<0.05)$. 

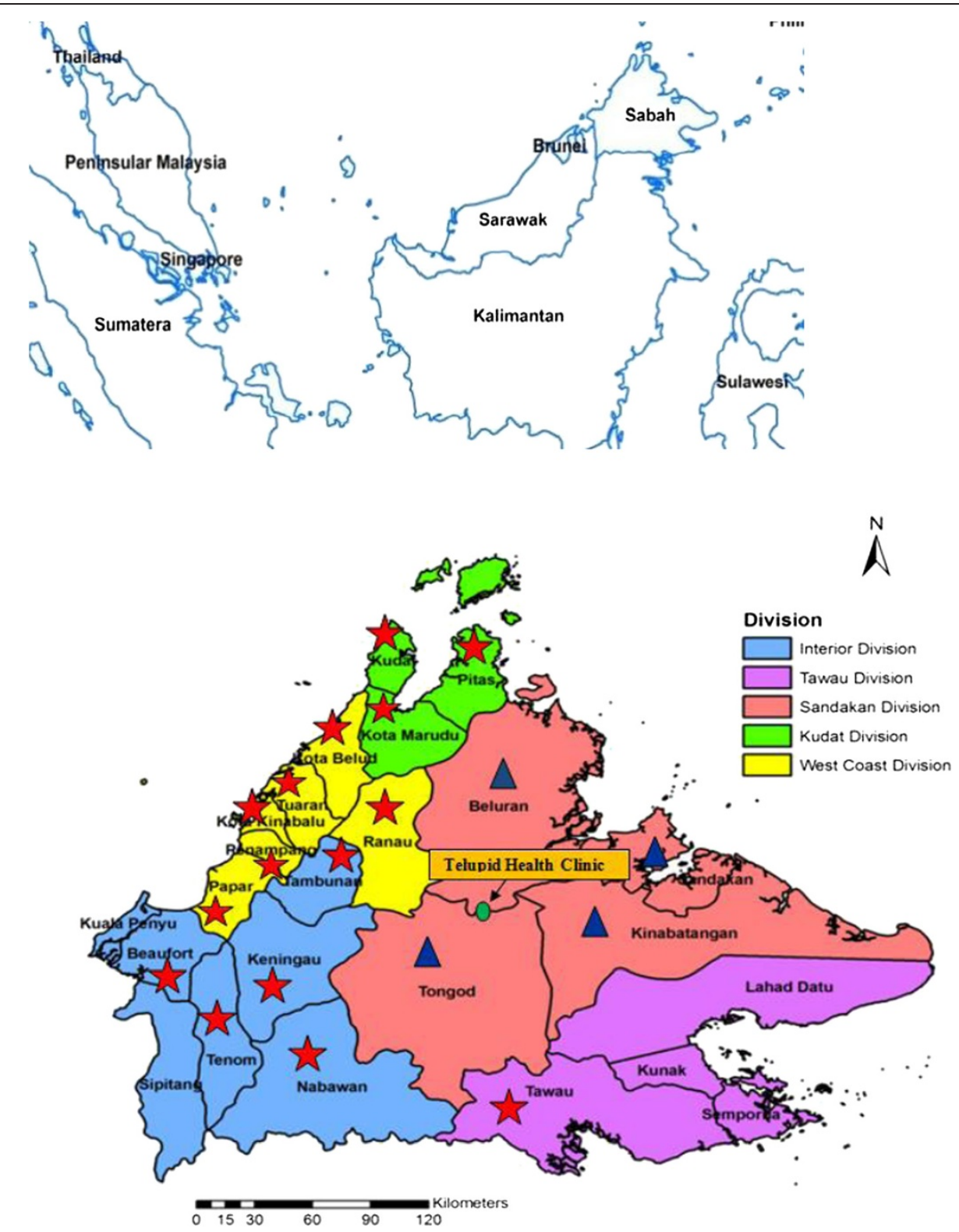

Figure 1 Location of human Plasmodium knowlesi infection in Sabah, Malaysia. The inset map of Southeast Asia shows the location of Sabah. Note: The location of human P. knowlesi detected in this study is marked by triangles. Stars represented the distribution of this parasite reported by previous studies [10,35-38].

cases of P. knowlesi were microscopically misdiagnosed as $P$. falciparum and three cases of $P$. knowlesi were also misdiagnosed as $P$. vivax (Table 1). Interestingly, $P$. knowlesi was detected in all four districts in Sandakan division and Kinabatangan had the highest incidence of $P$. knowlesi (31.6\%). Figure 1 showed the location of $P$. knowlesi cases detected in this study. No P. ovale was detected by using PlasmoNex ${ }^{\mathrm{Tm}}$. Six P. falciparum cases were misdiagnosed as $P$. malariae by microscopy examination as well as one mixed infection of $P$. falciparum/P. vivax was misdiagnosed as $P$. vivax/P. malariae (Table 1$)$.
Of the 178 PlasmoNex ${ }^{\text {ma }}$ positive samples, basic demographic data was obtained from 70 patients (69 with single infection, one with mixed infections). The haematological analysis of the present study focused only on single infection. Data showed that the patients within the age group 21-30 years $(39.1 \%)$ were the most susceptible group to malaria in this study (Table 4). There was a greater proportion of adult patients with $P$. vivax (24.6\%) compared to children (8.3\%) whereas the infection percentage for both $P$. falciparum and $P$. knowlesi patients was almost the same for adult and children. The oldest age range for patients 
with $P$. knowlesi infection were slightly higher (51-60 years old) than that of patients with P. falciparum and $P$. vivax (41-50 years old). The youngest child with PCR-confirmed knowlesi malaria was nine years old. This showed that patients with $P$. knowlesi infection demonstrated a wide age distribution (i.e., nine to 60 years). Among P. knowlesi infected patients, the percentage of male patients (95.0\%) was much higher compared to female patients (5.0\%) (Table 4).

Spearman's correlation co-efficients $\left(r_{s}\right)$ test was used to study the relationship between $\mathrm{Hb}$ value, platelet count and white blood cell count with parasite density. Overall, there was a significant correlation between parasite density with $\mathrm{Hb}$ value and platelet value but not with white blood cell count for all the species. There was a significant inverse correlation between parasite density with $\mathrm{Hb}$ value and platelet value. Moderate inverse correlation was noted between increasing parasite density and decreasing $\mathrm{Hb}$ value $\left(\mathrm{r}_{\mathrm{s}}=-0.317 ; \mathrm{p}=0.003\right)$. Likewise, the parasite density also significantly correlated with platelet value. Increasing parasite density correlated with decreasing platelet value $\left(r_{s}=-0.262, p=0.015\right)$ for all the Plasmodium species. As for TWBC, no significant correlation was observed with parasite density.
Anaemia was common in all species, occurring in 13 (39.4\%), nine (60.0\%) and nine (45.0\%) patients with P. falciparum, P. vivax and P. knowlesi malaria respectively (Table 5). Among patients with malaria parasite density ' ++++ ', knowlesi malaria patients showed the highest percentage of anaemia (80.0\%). Besides, the overall median concentration of platelet count for knowlesi patients $(75,500$ cells $/ \mathrm{cmm})$ was the lowest platelet counts compared to $P$. falciparum $(94000 \mathrm{cell} / \mathrm{cmm}$ ) and $P$. vivax $(103,000$ cells $/ \mathrm{cmm})$ malaria patients (Table 5). The TWBC level was almost the same regardless of malaria species.

The platelet count was further analysed according to malaria species. Thrombocytopaenia (platelet count $<150,000$ cells $/ \mathrm{cmm}$ ) was observed in all malaria species. There were 13 patients who had severe thrombocytopaenia, 27 patients had moderate thrombocytopaenia and 15 had mild thrombocytopaenia whereas 14 patients had no thrombocytopaenia (Table 6). Data showed that malaria patients were more frequently found to have moderate thrombocytopaenia $(39.1 \% ; 27 / 69)$ in this study. Patients with falciparum malaria $(6 / 13 ; 46.2 \%)$ were found to have the highest cases of severe thrombocytopaenia followed by knowlesi malaria patients $(5 / 13 ; 38.5 \%)$ and

Table 4 Demographic data for PCR-confirmed malaria positive patients in this study $(\mathrm{n}=69)$

\begin{tabular}{|c|c|c|c|c|c|c|c|c|c|c|}
\hline \multirow[t]{2}{*}{ Characteristics } & \multirow[b]{2}{*}{$\mathbf{N}$} & \multirow[b]{2}{*}{$\%$} & \multicolumn{2}{|c|}{ P. falciparum } & \multicolumn{2}{|c|}{ P. vivax } & \multicolumn{2}{|c|}{ P. knowlesi } & \multicolumn{2}{|c|}{ P. malariae } \\
\hline & & & $\mathbf{n}$ & $\%$ & $\mathbf{n}$ & $\%$ & $\mathbf{n}$ & $\%$ & $\mathbf{n}$ & $\%$ \\
\hline \multicolumn{11}{|l|}{ Gender } \\
\hline Male & 58 & 84.1 & 27 & 46.6 & 11 & 19.0 & 19 & 32.8 & 1 & 100.0 \\
\hline Female & 11 & 15.9 & 6 & 54.5 & 4 & 36.4 & 1 & 9.1 & 0 & 0 \\
\hline$x^{2}$ & & & & 0.2 & & 1.6 & & 2.5 & & 0.2 \\
\hline P & & & & 0.627 & & 0.200 & & 0.113 & & 0.661 \\
\hline \multicolumn{11}{|l|}{ Age groups } \\
\hline Children (0-14 years) & 12 & 17.4 & 6 & 50.0 & 1 & 8.3 & 4 & 33.3 & 1 & 8.3 \\
\hline Adults (>15 years) & 57 & 82.6 & 27 & 47.4 & 14 & 24.6 & 16 & 28.1 & 0 & 0 \\
\hline$x^{2}$ & & & & 0.03 & & 1.8 & & 0.1 & & 4.8 \\
\hline$P$ & & & & 0.868 & & 0.177 & & 0.715 & & 0.028 \\
\hline \multicolumn{11}{|l|}{ Age groups } \\
\hline $0-10$ & 8 & 11.6 & 4 & 28.6 & 1 & 7.1 & 2 & 14.3 & 1 & 7.1 \\
\hline $11-20$ & 14 & 20.3 & 6 & 37.5 & 4 & 25.0 & 4 & 25.0 & 0 & 0 \\
\hline $21-30$ & 27 & 39.1 & 13 & 41.9 & 7 & 22.6 & 7 & 22.6 & 0 & 0 \\
\hline $31-40$ & 11 & 15.9 & 6 & 50.0 & 1 & 8.3 & 4 & 33.3 & 0 & 0 \\
\hline $41-50$ & 6 & 8.7 & 4 & 50.0 & 2 & 25.0 & 0 & 0 & 0 & 0 \\
\hline $51-60$ & 3 & 4.3 & 0 & 0 & 0 & 0 & 3 & 75 & 0 & 0 \\
\hline$x^{2}$ & & & & 4.4 & & 4.0 & & 0.7 & & 5.1 \\
\hline P & & & & 0.500 & & 0.542 & & 0.084 & & 0.400 \\
\hline *Total & 69 & 100.0 & 33 & 47.8 & 15 & 21.7 & 20 & 29.0 & 1 & 1.5 \\
\hline
\end{tabular}

*Total samples were based on 69 PCR positive samples. Mixed infection was not included. 
vivax malaria patients $(1 / 13 ; 7.7 \%)$. This showed that $P$. falciparum and $P$. knowlesi patients had higher risk of getting severe thrombocytopaenia compared to $P$. vivax patients. Plasmodium falciparum patients also had the highest number of moderate thrombocytopaenia (12/27; 44.4\%) followed by P. knowlesi infected patients (9/27; $33.3 \%)$ and six of them were $P$. vivax-infected patients (6/ 27; 22.2\%) (Table 6).

\section{Discussion}

Malaria is one of the most severe parasitic infections and it is also a major public health problem in many countries in Southeast Asia. In the 1980s, the prevalence of malaria drastically decreased and was eliminated in many areas of Peninsular Malaysia due to the efficient malaria control programme. However, malaria is still prevalent in Malaysian Borneo and among the ethnic minority groups [39]. Recently, significant reductions in malaria cases have been observed and achieved in Malaysia [1]. Malaysia is now working to be malaria-free in the peninsula by 2015 and in Malaysian Borneo by $2020[1,40]$. However, recently, a significant increase (>ten-fold) of P. knowlesi cases was observed in Sabah between 2004 and 2011 and this trend threatens malaria elimination [41]. Since the early 2000s, it was reported that most districts of Sabah experienced an increase of $P$. knowlesi cases and it appeared to have begun in the south-west of Sabah (Interior division), followed by West Coast division and gradually progressed north-easterly (Kudat division). This increase appears to have begun initially in the Interior division and there was a steady increase of P. knowlesi cases from 2000 to 2011 in this region. West Coast division experienced an increase of P. knowlesi cases later, from 2001 to 2009. After that, the tip of Borneo, Kudat division experienced the most noticeable increase in $P$. knowlesi cases with more than 200 cases for the years 2009 and 2011. Plasmodium knowlesi infection has also been reported in eastern districts of Sabah (Sandakan and Tawau), although the cases reported in these two districts were fewer

Table 5 Intensity of malaria infections and the distribution of hematological status among malaria patients in this study $(n=69)^{\mathrm{a}}$

\begin{tabular}{|c|c|c|c|c|c|c|}
\hline \multirow[t]{2}{*}{ Malaria species and ${ }^{\mathrm{b}}$ parasitemia } & \multirow[b]{2}{*}{$\mathbf{N}$} & \multirow{2}{*}{$\begin{array}{l}\mathrm{Hb}(\mathrm{g} / \mathrm{l}) \\
\text { Median }\end{array}$} & \multirow{2}{*}{ 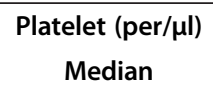 } & \multirow{2}{*}{$\begin{array}{c}\text { TWBC }\left(10^{3} \text { cells } / \mu \mathrm{l}\right) \\
\text { Median }\end{array}$} & \multicolumn{2}{|c|}{ Anaemia } \\
\hline & & & & & No. & $\%$ \\
\hline \multicolumn{7}{|l|}{ P. falciparum } \\
\hline+ & 5 & 140 & 127000 & 6.3 & 2 & 40.0 \\
\hline++ & 4 & 141 & 75500 & 7.0 & 0 & 0 \\
\hline+++ & 8 & 129 & 92500 & 6.3 & 4 & 50.0 \\
\hline++++ & 16 & 120.5 & 75500 & 8.2 & 7 & 43.8 \\
\hline Total & 33 & 132 & 94000 & 6.8 & 13 & 39.4 \\
\hline \multicolumn{7}{|l|}{ P. vivax } \\
\hline+ & 1 & 120 & 301000 & 10.3 & 1 & 100.0 \\
\hline++ & 6 & 135 & 108000 & 5.2 & 3 & 50.0 \\
\hline+++ & 4 & 120 & 127500 & 7.4 & 2 & 50.0 \\
\hline++++ & 4 & 118.5 & 71500 & 6.5 & 3 & 75.0 \\
\hline Total & 15 & 121 & 103000 & 6.3 & 9 & 60.0 \\
\hline \multicolumn{7}{|l|}{ P. knowlesi } \\
\hline+ & 1 & 130 & 63000 & 5.3 & 1 & 100.0 \\
\hline++ & 5 & 140 & 82000 & 7.8 & 1 & 20.0 \\
\hline+++ & 9 & 132 & 77000 & 6.7 & 3 & 33.3 \\
\hline++++ & 5 & 120 & 73000 & 6.6 & 4 & 80.0 \\
\hline Total & 20 & 130.5 & 75500 & 6.7 & 9 & 45.0 \\
\hline *Overall & 69 & 130 & 89000 & 6.6 & 31 & 44.9 \\
\hline
\end{tabular}

*Mixed infection was not included.

${ }^{\text {a }}$ Total samples were based on 69 PCR positive samples with complete hematological profiles.

$\mathrm{N}$ : number examined.

barasitemia:

$+=1-10$ parasites per 100 thin film fields.

$++=11-100$ parasites per 100 thin film fields.

$+++=1-10$ parasites per single thin film fields.

$++++=$ more than 10 parasites per single thin film fields. 
Table 6 Platelet counts in malaria patients according to different species detected by PCR in this study $(n=69)$

\begin{tabular}{|c|c|c|c|c|c|c|c|c|c|}
\hline \multirow{3}{*}{ Laboratory results } & \multicolumn{9}{|c|}{ Human Plasmodium species } \\
\hline & \multirow[t]{2}{*}{$\mathbf{N}$} & \multicolumn{2}{|c|}{ P. falciparum } & \multicolumn{2}{|c|}{ P. knowlesi } & \multicolumn{2}{|c|}{ P. vivax } & \multicolumn{2}{|c|}{ P. malariae } \\
\hline & & No. & $\%$ & No. & $\%$ & No. & $\%$ & No. & $\%$ \\
\hline \multicolumn{10}{|l|}{ Thrombocytopenia } \\
\hline Severe thrombocytopenia $<50,000$ cells/cmm & 13 & 6 & 46.2 & 5 & 38.5 & 1 & 7.7 & 1 & 7.7 \\
\hline Moderate thrombocytopenia 50,000-100,000 cells/cmm & 27 & 12 & 44.4 & 9 & 33.3 & 6 & 22.2 & 0 & 0 \\
\hline Mild thrombocytopenia 100,000-150,000 cells/cmm & 15 & 7 & 46.7 & 3 & 20.0 & 5 & 33.3 & 0 & 0 \\
\hline No thrombocytopenia $>150,000$ cells $/ \mathrm{cmm}$ & 14 & 8 & 57.1 & 3 & 21.4 & 3 & 21.4 & 0 & 0 \\
\hline${ }^{*}$ Total & 69 & 33 & 47.8 & 20 & 29.0 & 15 & 21.7 & 1 & 1.4 \\
\hline
\end{tabular}

*Mixed infections were not included.

compared to other districts, it has been increasing since 2008 [41]. Findings of the present study showed that $P$. knowlesi cases were also detected in the districts of Sandakan division. This shows that $P$. knowlesi is generally prevalent in Sabah. Therefore, the main objective of this study is to investigate the incidence and distribution of P. knowlesi as well as other human Plasmodium species in eastern Sabah.

Hexaplex PCR (or PlasmoNex ${ }^{\mathrm{Tm}}$ ) findings of the present study demonstrated that $P$. knowlesi were identified in 42 (23.6\%) samples, however, microscopic examination did not show $P$. knowlesi in any samples examined. Thirty-five infections diagnosed as $P$. malariae by microscopic examination were found to be $P$. knowlesi. This finding was similar to the studies carried out by other researchers in Malaysian Borneo [7,10,28,35], reporting that most microscopy-positive $P$. malariae infections were actually proven to be $P$. knowlesi infections when molecular approach was used. However, the transmission dynamics of this infection still remain unknown despite wide distribution of this parasite in Malaysian Borneo. The most prevalent Plasmodium species identified in the study was $P$. falciparum followed by $P$. vivax and $P$. knowlesi. It was reported that $P$. vivax was the most prevalent human malaria parasites in Malaysia [42], however, P. falciparum was found to be the most prevalent species in this study.

Conventional diagnostic technique, microscopic examination of asexual stages of Plasmodium on thin and thick blood films has been considered as the "gold standard" for the diagnosis of Plasmodium parasite infection because it is cost-effective and simple [43]. However, it can be rather challenging to diagnose mixed infections and infections with low level parasitaemia [44]. The diagnostic accuracy depends greatly on the experience of microscopists. Sensitivity of microscopy examination of malaria parasites can be affected by various factors such as the quality of staining, skills of the laboratory technician, expertise of microscopists and types of microscope used. In addition, microscopic identification of $P$. knowlesi is rather challenging due to its morphology, which is indistinguishable from $P$. falciparum and $P$. malariae. Underdiagnosis of $P$. knowlesi by microscopy examination was observed in the present study. Thus, molecular tool, such as PCR, is necessary to overcome the limitations of microscopy for malaria detection especially in generating epidemiology data.

The recently developed PlasmoNex ${ }^{\mathrm{TM}}$ [32], was used for the detection of malaria parasites and identification of the five human Plasmodium species in this study. Molecular methods based on DNA amplification have been used for malaria diagnosis since 1980s [45-49]. Several reports have shown that the DNA-based amplification methods had higher sensitivity (as low as 1 parasite/ $\mu$ l of blood) compared to microscopic examination of thin blood films, especially in cases of low parasitaemia or mixed infections [50-52]. Besides that, they are able to characterize each human malaria species [45,53-55].

PlasmoNex $^{\text {тм }}$ is a single-step hexaplex PCR system [32], which is able to detect all five species of human malaria with sensitivity below 0.5 parasites/ $\mu$ l of blood sample. To date, nested PCR is the molecular gold standard for the diagnosis of malaria and species identification. This method has been proven to be more specific and sensitive than conventional microscopy [30]. However, malaria diagnosis and species identification of malaria by nested PCR or semi-nested PCR are time consuming. The time required for hexaplex PCR is only three hours compared to semi-nested PCR which requires about five hours and approximately 14 hours for nested PCR, including the time for PCR preparation and gel electrophoresis. Besides, there are some other advantages of hexaplex PCR over the available nested PCR as it is less labour intensive, less contamination and reduced usage of reagents and consumables. Hexaplex PCR is a single-step system whereas semi-nested PCR required at least two PCR reactions and for nested PCR at least six PCR reactions are needed for the identification of all five Plasmodium species. The fewer PCR reactions reduce the usage of reagents and consumables and are also less labour intensive. Mixed infection detected by single-step hexaplex PCR in this study indicated that 
this system is robust and capable of detecting at least up to two species level mixed infections.

Recently, P. knowlesi cases had been reported in the Interior division and north-eastern state of Sabah $[10,28,35]$. It is obvious that the prevalence of P. knowlesi in Sabah has increased markedly and studies reported on the discovery of this parasite by using molecular approaches have greatly increased recently. In the early 1990s, there was around 50,000 malaria cases reported in Sabah and a continuous decrease was observed from the year 2001 to 2003. There were 6,050 cases in 2001, and this number fell to 5,096 cases in 2002 and subsequently to 1,770 cases in 2003 [56]. Previous report also showed that the notification of $P$. falciparum and $P$. vivax in Sabah had drastically decreased over the past decade [41]. The notification of P. falciparum and $P$. vivax had decreased to around 600 for the year 2011, however, a significant increase of $P$. knowlesi had occurred following the reduction of $P$. falciparum and $P$. vivax in Sabah. It showed that when human malaria cases decreased, $P$. knowlesi cases were on the rise. It is postulated that environmental changes together with decreasing rates of $P$. falciparum and $P$. vivax were likely to have contributed to the rise of $P$. knowlesi in Sabah [41]. Human activities such as extensive deforestation due to road construction work, oil palm plantation, timber or eco-tourism that occur in Sabah have brought human, macaques and mosquito vector into close contact and this propagates successful transmission of this parasite. In the present study, P. knowlesi infection was detected in all four districts of Sandakan divisions with the highest incidence of this parasite in the Kinabatangan region.

The wide distribution of $P$. knowlesi in this region is not surprising as this region is surrounded by dense primary and secondary forests which act as suitable habitats for mosquito vectors (i.e., forest-dwelling Anopheles balabacensis) [3] and macaques (i.e., long-tailed macaques, $M$. fascicularis and pig-tailed macaques, $M$. nemestrina) which are the natural hosts for $P$. knowlesi in Sabah. Previously, An. balabacensis was well recognized as the predominant vector of human malaria in Sabah [36]. However, Anopheles donaldi was reported to have replaced An. balabacensis in the Kinabatangan region in 2005 [56]. The peak outdoor feeding time for An. donaldi mosquitoes occurs between 18:00 and 19:00. This is the period most people are being bitten by this mosquito when the adults are working outside and children are having outdoor activities. Although $A n$. balabacensis was recognized as the vector of human malaria in Sabah, more studies should be carried out to investigate the current vector situation in this region. Perhaps, the situation of vectors in this region has changed due to recent development and mass forest clearance in the area. Nevertheless, communities should be informed to take necessary preventive measures against this parasite in order to prevent outbreaks of $P$. knowlesi infection.

Malaria patients who participated in the study comprised ages from young children to the elderly, however, this infection was more prevalent among adults especially the males. The epidemiological data showed that $P$. knowlesi malaria was diagnosed in male patients more often than in female patients, and only small proportion of knowlesi malaria cases occurred in children, this may be related to the limited outdoor or forest activities by this group of patients. These findings were in concordance with those reported from two studies in Sarawak [7,9], where a smaller proportion of knowlesi malaria occurred in children and no clustering of cases was reported. Findings of these two studies suggested that P. knowlesi infection occurs outside people's home and adults were the high risk group of this infection due to greater forest exposure, and it is postulated that human to human transmission did not occur. However, previous study postulated that the transmission of $P$. knowlesi may occur from human to human due to the discovery of family clustering cases [57]. Nevertheless, no clustering of $P$. knowlesi cases was found in the present study.

Microscopic findings showed that there were more gametocytes found in the P. falciparum and P. vivax samples compared to $P$. knowlesi samples. This could infer that infected humans were getting the knowlesi infection from mosquitoes that fed on monkeys and not from humans. Consistent with previous studies [9,35,57], patients with $P$. knowlesi were older than those with $P$. falciparum or $P$. vivax. The possible reason for the older age group being infected by $P$. knowlesi was discussed in a study done by William and his colleagues [41]. It was suggested that older individuals had greater forest exposure compared to the young. Patients aged between 21 to 30 years old were the group with the highest number of malaria cases detected in this study, possibly due to greater forest activity by this group, who either work or stay in the forest, such as timber and oil palm plantations workers, since the economic activities in Kinabatangan are the timber industry and oil palm plantations and the highest cases of $P$. knowlesi were detected in this district. Long working hours in the forest may increase the risk of exposure to the mosquito vectors, resulting in successful transmission of $P$. knowlesi. Despite these observations, epidemiological risk factor of $P$. knowlesi malaria still remains unclear, hence further investigations are required in order to develop successful control strategies for knowlesi malaria.

The symptoms of human P. knowlesi infection are almost similar to the other four human malaria species, however, it is more severe than the disease caused by 
P. vivax and more virulent because it has a short lifecycle of 24 hours [58] which leads to hyperparasitaemia enabling a fast progression of the disease. Malaria is frequently associated with a variety of haematological complications such as thrombocytopaenia and anaemia and both have high mortality rates [9,35,57,59-61]. A healthy human platelet count ranges from 150,000 to 450,000 platelets per microlitre of blood, levels lower than this range is considered as thrombocytopaenia. It is one of the common features of acute malaria and this occurs in P. knowlesi [9,15,35,62-64], P. falciparum [65,66] and $P$. vivax [66] infections regardless of severity of infection.

The present study showed similar results with previous studies whereby thrombocytopaenia occurred in all species of human malaria parasites indicating that thrombocytopaenia is a common feature of malaria and its occurrence should increase the suspicion of malaria. However, there are several other causes of thrombocytopaenia such as leukaemia, hereditary syndromes, HIVassociated thrombocytopaenia and also dengue fever. Thrombocytopaenia can be caused by decreased platelet production or peripheral destruction. It is postulated that malarial antigen caused the lysis of immune complexes, which leads to sequestration of the injured platelet by macrophages in the spleen $[67,68]$. However, the exact mechanism of thrombocytopaenia in malaria is not clear and requires further investigation. Findings of the present study demonstrated that most of the $P$. falciparum patients suffered severe and moderate thrombocytopaenia followed by $P$. knowlesi and $P$. vivax patients. This might explain the role of platelet activation in the pathogenesis of liver-attacking malaria. Platelets are produced by a process called thrombopoiesis, which occurs in the bone marrow by budding off from megakaryocytes. Thrombopoietin is a hormone that is secreted for the regulation of platelet production and megakaryocytes. This hormone is produced by the liver and kidneys. Hyperparasitaemia of P. falciparum and P. knowlesi parasites due to their shorter lifecycle may destruct the production of this hormone in the liver and thus decreased the production of platelet and caused thrombocytopaenia. However, this hypothesis requires further investigation. Many studies have shown that P. knowlesi patients suffered severe thrombocytopaenia $[28,35,69,70]$. Findings of the present study were in parallel with the study done by Barber and her colleagues in 2011 [35] where platelet counts of patients were lower in P. knowlesi than in P. falciparum malaria. Besides, findings of the present study are also in line with the study conducted by Patel and his colleagues [66] which reported that patients with $P$. falciparum malaria were found to have lower platelet counts than patients with $P$. vivax malaria. Therefore, findings of present study demonstrated that the platelet count of P. knowlesi- infected patients were lower than those in $P$. falciparum-infected patients and $P$. vivax-infected patients, which, in turn, were lower than those in the uninfected patients and a platelet count below 75,500 cells/cmm should increase the suspicion of $P$. knowlesi infection. Nonetheless, it is suggested that in order to verify this hypothesis, more samples need to be included in future. It is believed that thrombocytopaenia is more common in P. falciparum malaria compared to $P$. vivax malaria. However, recent studies have shown the trend that thrombocytopaenia was found to be equally common in P. vivax malaria compared to P. falciparum [71-74]. A study conducted by George and Alexander [75] reported significant thrombocytopaenia in $P$. vivax malaria. The findings were in accordance with those in Brazil [76] and Qatar [77]. Although the relation between thrombocytopaenia and the species of malaria is unclear, it is a fact that thrombocytopaenia is universal in malariainfected patients and should act as a significant indicator of malaria especially knowlesi malaria.

Anaemia is also another haematological complication that is usually associated with malaria especially in P. knowlesi and P. falciparum infections $[35,57,78]$. The present study also highlighted that anaemia was observed in all species of malaria patients including $P$. knowlesi patients indicating that anaemia is common in human malaria infections. However, malarial anaemia appears to be multifactorial, factors such as genetic disorders (e.g., thalassaemia), haemoglobinopathies, poor dietary intake and socio-economic causes may also contribute to anaemia. It was observed that anaemia is significantly higher in female patients $\left(\mathrm{X}^{2}=5.1 ; \mathrm{p}=0.025\right)$ compared to male patients in the present study. This might also be due to blood loss of female during menstruation. With regard to age, the present study demonstrated that the prevalence of anaemia was significantly higher $\left(\mathrm{X}^{2}=6.30 ; \mathrm{p}=0.012\right)$ in children compared to adults. This is in agreement with other previous studies where malaria-related anaemia is more severe in children rather than in adults $[79,80]$ due to increased demand of iron by the body as growth is rapid in children. In 2002, Praba-Egge and her colleagues [81] carried out experimental infection of non-human primates with P. knowlesi and Plasmodium cynomolgi. The study reported that anaemia was observed in P. knowlesiinfected monkeys after primary and/or repeated infection. Severe anaemia was notable in macaques after repeated infection by $P$. knowlesi [81]. This showed that anaemia was common in both $P$. knowlesi-infected humans or macaques. Malaria-related anaemia is a consequence of hyperparasitaemia and it has been associated with immune-mediated lysis of erythrocytes by schizonts or erythrophagocytosis in the spleen. Findings of the present study showed that both anaemia and 
thrombocytopaenia are common in malaria-infected patients, including $P$. knowlesi patients.

There was a significant inverse correlation between parasite density with $\mathrm{Hb}$ and platelet value for all the species of malaria in the present study. This was in line with other studies where malaria-infected patients tended to have significantly lower $\mathrm{Hb}$ levels and platelet counts $[9,82]$. The trend of increasing parasite density with decreasing platelet count observed in the present study has been previously reported for $P$. falciparum $[83,84]$ but not $P$. vivax [85]. However, detailed study on the relation between parasite density and platelet count for human P. knowlesi infection was scarce. This showed that more investigations have to be conducted in order to study the correlation of platelet count with parasite density in malaria infection. Low $\mathrm{Hb}$ level due to increased parasite density might be explained by increased haemolysis or decreased rate of erythrocyte production due to the invasion of erythrocytes by malaria parasite $[80,86]$.

White blood cell count (WBC) during malaria are usually characterized as being low to normal $[59,87]$, a decrease in the number of WBC (leukocytes) in the blood is known as leukopaenia whereas elevated WBC refers to leukocytosis. Findings demonstrated that only a small proportion of the malaria patients in the present study suffered leukopaenia and leukocytosis, however, this may be due to the small sample size in the present study. Results showed that the WBC for P. vivax malaria patient was lower than $P$. falciparum malaria patient, which was in contrast to previous study where WBC in P. falciparum patients were lower than those in $P$. vivax-infected patients and, in turn, lower than those in healthy patients [87]. Overall, the TWBC of patients for all the malaria species detected in the present study were generally within the normal range.

The present study had several limitations. Firstly, haematological profiles such as $\mathrm{Hb}$ level, platelet counts and TWBC were only available for 85 patients. The statistical analyses of these parameters were mostly not significant due to the small sample size. Secondly, the baseline demographic data is incomplete and, unfortunately, detailed clinical features of patients could not be retrieved. There were several reasons for the incomplete data in the study. Demographic data and haematological profiles were unable to be retrieved for the samples that were sent from other districts of the division to the clinic. Case notes of all these patients were kept in the respective hospital or clinic therefore the data required were not available. In addition, sometimes, patients with severe malaria were referred to the district hospitals immediately before the full blood profiles were tested in the clinic. There were also some patients with uncomplicated malaria who have refused admission and, therefore, full blood counts were unable to be performed. Thirdly, travel history of patients was not available and therefore the information on where patients acquired malaria infection, especially P. knowlesi infection, could not be deduced. Nevertheless, despite all these limitations, this study is one of the few comprehensively analysed studies on the occurrence and epidemiology study of malaria in the eastern districts of Sabah.

\section{Conclusion}

Present study revealed that most of the $P$. knowlesi infection in Sandakan division was misdiagnosed as $P$. malariae by microscopic examination. The wide distribution of human P. knowlesi infection indicated that this parasite is generally able to infect humans and there is high potential for knowlesi outbreak to occur given that the full knowledge of the dynamics of transmission between human-monkey-mosquito is not adequately understood. This study also observed that there was no clustering of cases of $P$. knowlesi suggesting that transmission may occur in forested areas away from people's homes. In addition, given that microscopic findings showed that gametocytes were only detected in two $P$. knowlesi patients, indicating that there was less chance of human to human transmission occurring. With regard to haematological analysis, thrombocytopaenia and anaemia was shown to be the most frequent malaria-associated haematological complications. However, larger prospective studies are needed to investigate the relations between parasite species as well as the parasite density to the haematological complications associated with malaria. It is crucial that prospective studies on epidemiological risk factors and transmission dynamics of $P$. knowlesi in these areas are comprehensive in order to accrue accurate epidemiological data, which serves as an imperative foundation in formulating effective malaria control measures that will subsequently contribute to the successful elimination of malaria in Malaysia by 2020. In order to reduce mortality, it is pertinent for malariae suspected samples to be confirmed by PCR. The availability of advanced diagnostic tool PlasmoNex ${ }^{\mathrm{mm}}$ enhanced the accuracy and accelerated the speed in the diagnosis of malaria. Given the severity of knowlesi malaria and its fatality, confirmed P. knowlesi cases should be reported as such by the doctors treating these cases so that the actual disease burden is known.

\section{Competing interests}

The authors declare that they have no competing interests.

\section{Authors' contributions}

YALL, IV and KHC conceived and designed the experiments. PCL and VN carried out the laboratory diagnosis. XTG, CHC and NJY carried out the molecular genetic studies. XTG, RN and TCT analysed the data. XTG, YALL, TCT and IV drafted the manuscript. KHC, PCL and YALL contributed the reagents/materials/analysis tools. All authors read and approved the final manuscript. 


\section{Acknowledgements}

We would like to thank Mr. Sukri from Telupid Health Clinic, Sabah for the assistance in sample collection and retrieving the medical records of patients; the staff of this clinic for their assistance throughout the study and all who provided blood samples. This work was supported by funds from University of Malaya High Impact Research (J-20011-73822 for IV and YALL), University of Malaya Research Grant (UMRG) (RG192/10HTM for TCT) and University of Malaya Student Grant (XTG, NJY).

\section{Author details}

'Department of Parasitology, Faculty of Medicine, University of Malaya, Kuala Lumpur, Malaysia. ${ }^{2}$ Department of Molecular Medicine, Faculty of Medicine, University of Malaya, Kuala Lumpur, Malaysia. ${ }^{3}$ School of Science and Technology, Universiti Malaysia Sabah, Kota Kinabalu, Sabah, Malaysia.

Received: 4 June 2013 Accepted: 22 July 2013

Published: 31 July 2013

\section{References}

1. World Health Organization: World Malaria Report 2011. Available http:// www.who.int/malaria/world_malaria_report_2011/9789241564403_eng.pdf Accessed 3rd May 2012.

2. Ministry of Health Malaysia: Country Briefing 2012. Available http://apmen. org/storage/country-briefings/Malaysia.pdf Accessed 1st June 2013.

3. Hii JLK: Anopheles malaria vector in Malaysia with reference to Sabah. In Problems of Malaria in SEAMIC Countries. Edited by Harinasuta C, Reynolds DC. Tokyo: Southeast Asian Medical Information Center; 1985:71-81.

4. Lee KS, Divis PC, Zakaria SK, Matusop A, Julin RA, Conway DJ, Cox-Singh J, Singh B: Plasmodium knowlesi: reservoir hosts and tracking the emergence in humans and macaques. PLOS Pathog 2011, 7:e1002015.

5. White NJ: Plasmodium knowlesi: the fifth human malaria parasite. Clin Infect Dis 2008, 46:172-173.

6. Garnham PCC: Malaria parasites and other hemosporidia. Oxford, UK: Blackwell Scientific; 1966

7. Singh B, Lee KS, Matusop A, Radhakrihsnan A, Shamsul SSG, Cox-Singh J, Thomas A, Conway DJ: A large focus of naturally acquired Plasmodium knowlesi infections in human beings. Lancet 2004, 363:1017-1024.

8. Cox-Singh J, Davis TME, Lee KS, Shamsul SSG, Matusop A, Ratnam S, Conway DJ, Singh B: Plasmodium knowlesi malaria in humans is widely distributed and potentially life-threatening. Clin Infect Dis 2008, 15:165-171.

9. Daneshvar C, Davis TM, Cox-Singh J, Rafa'ee MZ, Zakaria SK, Divis PCS, Singh B: Clinical and laboratory features of human Plasmodium knowlesi infection. Clin Infect Dis 2009, 49:852-860.

10. Lau TY, Joveen-Neoh WF, Chong KL: High Incidence of Plasmodium knowlesi Infection in the Interior Division of Sabah, Malaysian Borneo. Int J Biosci Biochem Bioinform 2011, 1:163-167.

11. William T, Menon J, Rajahram G, Chan L, Ma G, Donaldson S, Khoo S, Fredrick C, Jelip J, Anstey NM, Yeo TW: Severe Plasmodium knowlesi malaria in a tertiary hospital, Sabah, Malaysia. Emerg Infect Dis 2011, 17:1248-1255.

12. Kantele A, Marti H, Felger I, Muller D, Jokiranta TS: Monkey malaria in a European traveler returning from Malaysia. Emerg Infect Dis 2008, 14:1434-1436.

13. Vythilingam I, Noorazian YM, Huat TC, Jiram Al, Yusri YM, Azahari AH, Norparina I, Noorrain A, Lokmanhakim S: Plasmodium knowlesi in humans, macaques and mosquitoes in peninsular Malaysia. Parasit Vectors 2008, 1:26.

14. Lee CE, Adeeba K, Freigang G: Human Plasmodium knowlesi Infections in Klang Valley, Peninsula Malaysia: A Case Series. Med J Malaysia 2010, 65:63-65.

15. Ng OT, Ooi EE, Lee CC, Lee PJ, Ng LC, Pei SW, Tu TM, Loh JP, Leo YS: Naturally acquired Plasmodium knowlesi infection, Singapore. Emerg Infect Dis 2008, 14:814-816.

16. Ong CW, Lee SY, Koh WH, Ooi EE, Tambyah PA: Monkey malaria in humans: a diagnostic dilemma with conflicting laboratory data. Am J Trop Med Hyg 2009, 80:927-928.

17. Jeslyn WP, Huat TC, Vernon L, Irene LM, Sung LK, Jarrod LP, Singh B, Ching NL: Molecular epidemiological investigation of Plasmodium knowlesi in humans and macaques in Singapore. Vector Borne Zoonotic Dis 2011, 11:131-135.

18. Putaporntip C, Hongsrimuang T, Seethamchai S, Kobasa T, Limkittikul K, Cui $L$, Jongwutiwes S: Differential prevalence of Plasmodium infections and cryptic Plasmodium knowlesi malaria in humans in Thailand. J Infect Dis 2009, 199:1143-1150.
19. Sermwittayawong $N$, Singh B, Nishibuchi M, Sawangjaroen N, Vuddhakul V: Human Plasmodium knowlesi infection in Ranong province, southwestern border of Thailand. Malar J 2012, 11:36.

20. Zhu HM, Li J, Zheng H: Human natural infection of Plasmodium knowlesi. Chin J Parasitol Parasit Dis 2006, 24:70-71.

21. Jiang N, Chang Q, Sun X, Lu H, Yin J, Zhang Z, Wahlgren M, Chen Q: Coinfections with Plasmodium knowlesi and other malaria parasites, Myanmar. Emerg Infect Dis 2010, 16:1476-1478.

22. Luchavez J, Espino F, Curameng P, Espina R, Bell D, Chiodini P, Nolder D, Sutherland C, Lee K, Singh B: Human infections with Plasmodium knowlesi, the Philippines. Emerg Infect Dis 2008, 14:811-813.

23. Figtree M, Lee R, Bain L, Kennedy T, Mackertich S, Urban M, Cheng Q, Hudson BJ: Plasmodium knowlesi in human, Indonesian Borneo. Emerg Infect Dis 2010, 16:672-674.

24. Sulistyaningsih E, Fitri LE, Löscher T, Berens-Riha N: Diagnostic difficulties with Plasmodium knowlesi infection in human. Emerg Infect Dis 2010, 16:1033-1034

25. Eede P, Van HN, Van Overmeir C, Vythilingam I, Duc T, Hung L, Manh H, Anne J, D'Alessandro U, Erhart A: Human Plasmodium knowlesi infections in young children in central Vietnam. Malar J 2009, 8:249.

26. Khim N, Siv S, Kim S, Mueller T, Fleischmann E, Singh B, Cliff P, Divis S, Steenkeste N, Duval L, Bouchier C, Duong S, Ariey F, Menard D: Plasmodium knowlesi infection in humans, Cambodia, 2007-2010. Emerg Infect Dis 2011, 17:1900-1902.

27. Cox-Singh J, Hiu J, Lucas SB, Divis PC, Zulkarnaen M, Chandran P, Wong KT, Adem P, Zaki SR, Singh B: Severe malaria - a case of fatal Plasmodium knowlesi infection with post-mortem findings: a case report. Malar J 2010, 9:10.

28. Rajahram G, Barber BE, William T, Menon J, Anstey NM, Yeo TW: Deaths due to Plasmodium knowlesi malaria in Sabah, Malaysia: association with reporting as P. malariae and delayed parenteral artesunate. Malar J 2012, 11:284.

29. Lee KS, Cox-Singh J, Brooke G, Matusop A, Singh B: Plasmodium knowlesi from archival blood films: further evidence that human infections are widely distributed and not newly emergent in Malaysian Borneo. Int J Parasitol 2009, 39:1125-1128.

30. Singh B, Bobogare A, Cox-Singh J, Snounou G, Abdullah MS, Rahman HA: A genus- and species-specific nested polymerase chain reaction malaria detection assay for epidemiologic studies. Am J Trop Med Hyg 1999, 60:687-692.

31. Joveen-Neoh WF, Chong KL, Wong CM, Lau TY: Incidence of malaria in the Interior Division of Sabah, Malaysian Borneo, based on nested PCR. J Parasitol Res 2011. doi:10.1155/2011/104284.

32. Chew CH, Lim YA, Lee PC, Mahmud R, Chua KH: Hexaplex PCR detection system for identification of five human Plasmodium species with an internal control. J Clin Microbiol 2012, 50:4012-4019.

33. Elliot J: Manual of Basic Techniques for a Health Laboratory. 2nd edition. Bull World Health Organ 2004, 82:229.

34. World Health Organization: Iron deficiency anaemia. Assessment, prevention, and control. A guide for programme managers. Geneva: World Health Organization; 2001

35. Barber BE, William T, Jikal M, Jilip J, Dhararaj P, Menon J, Yeo TW, Anstey NM: Plasmodium knowlesi malaria in children. Emerg Infect Dis 2011, 17:814-820.

36. Hii JL: Evidence for the existence of genetic variability in the tendency of Anopheles balabacensis to rest in houses and to bite man. Southeast Asian J Trop Med Public Health 1985, 16:173-182.

37. Naing DKS, Anderios F, Lin Z: Geographic and ethnic distribution of P. knowlesi infection in Sabah, Malaysia. Int J Collab Res Intern Med Public Health 2011, 3:391-400

38. Barber BE, William T, Grigg MJ, Menon J, Auburn S, Marfurt J, Anstey NM, Yeo TW: A prospective comparative study of knowlesi, falciparum and vivax malaria in Sabah, Malaysia: high proportion with severe disease from Plasmodium knowlesi and $P$. vivax but no mortality with early referral and artesunate therapy. Clin Infect Dis 2013, 56:383-397.

39. World Health Organization: Malaysia Malaria Profile. Geneva: World Health Organization; 2010.

40. Rundi C: Malaria Elimination in Malaysia. Kota Kinabalu, Sabah Malaysia: Third annual meeting of the Asia Pacific Malaria Elimination Network (APMEN); 2011. Available: http://apmen.org/apmen-iii-meeting-proceedings/ Accessed 3rd May 2012.

41. William T, Rahman HA, Jelip J, Ibrahim MY, Menon J, Grigg MJ, Yeo TW, Anstey NM, Barber BE: Increasing incidence of Plasmodium knowlesi malaria following control of $P$. falciparum and $P$. vivax Malaria in Sabah, Malaysia. PLoS Negl Trop Dis 2013, 7:e2026. 
42. Ministry of Health Malaysia: Country Updates Malaysia 2010. Malaysia: Ministry of Health; 2012.

43. Singh B: Molecular methods for diagnosis and epidemiological studies of parasitic infections. Int J Parasitol 1997, 27:1135-1145.

44. Genc A, Eroglu F, Koltas IS: Detection of Plasmodium vivax by nested PCR and real-time PCR. Korean J Parasitol 2010, 48:99-103.

45. Snounou G, Viriyakosol S, Zhu XP, Jarra W, Pinheiro L, Rosario VE do, Thaithong S, Brown KN: High sensitivity of detection of human malaria parasites by the use of nested polymerase chain reaction. Mol Biochem Parasitol 1993, 61:315-320.

46. Waters AP: The ribosomal RNA genes of Plasmodium. Adv Parasitol 1994, 34:33-79.

47. Farcas GA, Zhong KJ, Lovegrove FE, Graham CM, Kain KC: Evaluation of the Binax NOW ICT test versus polymerase chain reaction and microscopy for the detection of malaria in returned travelers. Am J Trop Med Hyg 2003, 69:589-592.

48. Patsoula E, Spanakos G, Sofianatou D, Parara M, Vakalis NC: A single-step, PCR-based method for the detection and differentiation of Plasmodium vivax and P. falciparum. Ann Trop Med Parasitol 2003, 97:15-21.

49. Speers DJ, Ryan S, Harnett G, Chidlow G: Diagnosis of malaria aided by polymerase chain reaction in two cases with low-level parasitaemia. Intern Med J 2003, 33:613-615.

50. Brown AE, Kain KC, Pipithkul J, Webster HK: Demonstration by the polymerase chain reaction of mixed Plasmodium falciparum and $P$. vivax infections undetected by conventional microscopy. Trans $R$ Soc Trop Hyg 1992, 86:609-612.

51. Ciceron L, Jaureguiberry G, Gay F, Danis M: Development of a Plasmodium PCR for monitoring efficacy of antimalarial treatment. J Clin Microbiol 1999, 37:35-38.

52. Morassin B, Fabre R, Berry A, Magnaval JF: One year's experience with the polymerase chain reaction as a routine method for the diagnosis of imported malaria. Am J Trop Med Hyg 2002, 66:503-508.

53. Rubio JM, Benito A, Berzosa PJ, Roche J, Puente S, Subirats M, Lopez-Velez R, Garcia L, Alvar J: Usefulness of seminested multiplex PCR in surveillance of imported malaria in Spain. J Clin Microbiol 1999, 37:3260-3264.

54. Rubio JM, Benito A, Roche J, Berzosa PJ, Garcia ML, Mico M, Edu M, Alvar J: Semi-nested, multiplex polymerase chain reaction for detection of human malaria parasites and evidence of Plasmodium vivax infection in Equatorial Guinea. Am J Trop Med Hyg 1999, 60:183-187.

55. Rubio JM, Buhigas I, Subirats M, Baquero M, Puente S, Benito A: Limited level of accuracy provided by available rapid diagnosis tests for malaria enhances the need for PCR-based reference laboratories. J Clin Microbiol 2001, 39:2736-2737.

56. Vythilingam I, Chan ST, Shanmugratnam C, Tanrang H, Chooi KH: The impact of development and malaria control activities on its vectors in the Kinabatangan area of Sabah, East Malaysia. Acta Trop 2005, 96:24-30

57. Barber BE, William T, Dhararaj P, Anderios F, Grigg MJ, Yeo TW, Anstey NM: Epidemiology of Plasmodium knowlesi malaria in north-east Sabah, Malaysia: family clusters and wide age distribution. Malar J 2012, 11:401.

58. Coatney GR, Collins WE, Warren M, Contacos PG: The primate malarias [original book published 1971] [CD-ROM]. Version 1.0. Centers for. Atlanta: Disease Control and Prevention; 2003.

59. Reiley CG, Barrett $\mathrm{O} \mathrm{Jr}$ : Leukocyte response in acute malaria. Am J Med Sci 1971, 262:153-158.

60. Singh B, Daneshvar C: Plasmodium knowlesi Malaria in Malaysia. Med J Malaysia 2010, 65:3.

61. Khan SJ, Abbass Y, Marwat MA: Thrombocytopenia as an indicator of malaria in adult population. Malar Res Treat 2012, 405981. doi:10.1155/ 2012/405981.

62. Jongwutiwes S, Putaporntip C, Iwasaki T, Sata T, Kanbara H: Naturally acquired Plasmodium knowlesi malaria in human in Thailand. Emerg Infect Dis 2004, 12:22113.

63. Bronner U, Divis PC, Farnert A, Singh B: Swedish traveller with Plasmodium knowlesi malaria after visiting Malaysian Borneo. Malar J 2009, 8:15.

64. Ta TT, Salas A, Ali-Tammam M, Martinez Mdel C, Lanza M, Arroyo E, Rubio JM: First case of detection of Plasmodium knowlesi in Spain by Real Time PCR in a traveller from Southeast Asia. Malar J 2010, 9:219.

65. Moulin F, Lesage F, Legros AH, Maroga C, Moussavou A, Guyon P, Marc E, Gendrel D: Thrombocytopenia and Plasmodium falciparum malaria in children with different exposures. Arch Dis Child 2003, 88:540-541.

66. Patel U, Gandhi G, Friedman S, Niranjan S: Thrombocytopenia in malaria. J Natl Med Assoc 2004, 96:1212-1214
67. Mehrunnisa A, Wajihullah, Saifi MA, Khan HM: Prevalence of malaria in Aligarh. J Commun Dis 2002, 34:70-77.

68. Park JW, Park SH, Yeom JS, Huh AJ, Cho YK, Ahn JY, Min GS, Song GY, Kim YA, Ahn SY, Woo SY, Lee BE, Ha EH, Han HS, Yoo K, Seoh JY: Serum cytokine profiles in patients with Plasmodium vivax malaria: a comparison between those who presented with and without thrombocytopenia. Ann Trop Med Parasitol 2003, 97:339-344.

69. Willmann M, Ahmed A, Siner A, Wong IT, Woon LC, Singh B, Krishna S, Cox-Singh J: Laboratory markers of disease severity in Plasmodium knowlesi infection: a case control study. Malar J 2012, 11:363.

70. Lee WC, Chin PW, Lau YL, Chin LC, Fong MY, Yap CJ, Supramaniam RR, Mahmud R: Hyperparasitaemic human Plasmodium knowlesi infection with atypical morphology in peninsular Malaysia. Malar J 2013, 12:88.

71. Aggarwal A, Rath S, Shashiraj: Plasmodium vivax malaria presenting with severe thrombocytopenia. J Trop Pediatr 2005, 51:120-121.

72. Kaur D, Wasir V, Gulati S, Bagga A: Unusual presentation of Plasmodium vivax malaria with severe thrombocytopenia and acute renal failure. J Trop Pediatr 2007, 53:210-212.

73. Harish R, Gupta S: Plasmodium vivax malaria presenting with severe thrombocytopenia, cerebral complications and hydrocephalus. Indian J Pediatr 2009, 76:551-552

74. Bhatia $V$, Bhatia J: Severe thrombocytopenia with bleeding manifestations in two children secondary to Plasmodium vivax. Platelets 2010, 21:307-309.

75. George P, Alexander LM: A study on the clinical profile of complicated Plasmodium vivax mono-infections. Asian Pac J Trop Med 2010, 3:560-562.

76. Silva SBR: Avaliac, ao da frequência e dos fatores associados à plaquetopenia causada pelo Plasmodium vivax [MSc Thesis]. Mato Grosso, Brazil: Universidade Federal do Mato Grosso; 2009.

77. Khan FY, Lutof AK, Yassin MA, Khattab MA, Saleh M, Rezeq HY, Almaslamani M: Imported malaria in Qatar: a one year hospital-based study in 2005. Travel Med Infect Dis 2009, 7:111-117.

78. Jadhav UM, Singhvi R, Shah R: Prognostic implications of white cell differential count and white cell morphology in Malaria. J Postgrad Med 2003, 49:218-220. discussion 221.

79. Menendez C, Fleming AF, Alonso PL: Malaria-related anaemia. Parasitol Today 2000, 16:469-476.

80. Phillips RE, Pasvol G: Anaemia of Plasmodium falciparum malaria. Baillieres Clin Haematol 1992, 5:315-330.

81. Praba-Egge AD, Montenegro S, Cogswell FB, Hopper T, James MA: Cytokine responses during acute simian Plasmodium cynomolgi and Plasmodium knowlesi infections. Am J Trop Med Hyg 2002, 67:586-596.

82. Erhart LM, Yingyuen K, Chuanak N, Buathong N, Laoboonchai A, Miller RS, Meshnick SR, Gasser RA Jr, Wongsrichanalai C: Hematologic and clinical indices of malaria in a semi-immune population of western Thailand. Am J Trop Med Hyg 2004, 70:8-14.

83. Rojanasthien S, Surakamolleart V, Boonpucknavig S, Isarangkura P: Hematological and coagulation studies in malaria. J Med Assoc Thai 1992, 1(75 Suppl):190-194.

84. Richards MW, Behrens RH, Doherty JF: Short report: hematologic changes in acute, imported Plasmodium falciparum malaria. Am J Trop Med Hyg 1998, 59:859.

85. Kochar DK, Tanwar GS, Agrawal R, Kochar S, Tanwar G, Falodia SK, Kochar A, Middha S, Kochar SK: Platelet count and parasite density: independent variable in Plasmodium vivax malaria. J Vector Borne Dis 2012, 49:191-192.

86. Weatherall DJ: The anaemia of malaria. In Malaria: Principles and Practice of Malariology. Edited by McGregor I, Wernsdorfer WH. New York: Churchill Livingstone; 1988:735-751.

87. McKenzie FE, Prudhomme WA, Magill AJ, Forney JR, Permpanich B, Lucas C, Gasser RA Jr, Wongsrichanalai C: White blood cell counts and malaria. $\mathrm{J}$ Infect Dis 2005, 192:323-330.

doi:10.1186/1475-2875-12-264

Cite this article as: Goh et al:: Increased detection of Plasmodium knowlesi in Sandakan division, Sabah as revealed by PlasmoNex ${ }^{\mathrm{TM}}$. Malaria Journal 2013 12:264. 